\title{
AN
}

\section{Los Simpson, un fenómeno social con 20 años de permanencia en la programación televisiva}

\section{The Simpsons, a 20social phenomenon of stay in television programming}

\author{
Carmen Marta Lazo \\ Profesora Titular de Comunicación Audiovisual y Publicidad. \\ Universidad de Zaragoza. \\ cmarta@unizar.es \\ Alejandro Tovar Lasheras \\ Magíster Universidad Complutense de Madrid. \\ atovarlasheras@gmail.com
}

\section{Resumen}

El hecho de que una serie de animación se convierta en un clásico de la antena televisiva, con veinte años de vigencia, no es casualidad. Son muchos los factores que repercuten en que un espacio mediático se instaure impertérrito en la parrilla de programación: el formato, el tratamiento, el contenido o el horario de emisión, entre otros. En el presente artículo analizamos cada una de las claves por las que consideramos que Los Simpson se han convertido en un referente para todos los públicos, en especial para los niños. Incluimos un estudio llevado a cabo con dieciséis grupos de discusión compuestos por niños entre 7 y 12 años, para definir los motivos por los que esta serie es una de sus preferidas de toda la programación televisiva y justificar de qué modo entienden la violencia que contiene.

\section{Abstract}

The fact that an animated series has become a classic on television and been on the air for the last twenty years is no coincidence. There are many factors contributing to the reasons why a television programme establishes itself indefinitely on a programme schedule: format, handling, content or broadcast time schedule, among others. This article analyses each of the key features as to why we consider The Simpsons have become a point of reference for all kinds of audiences, especially children. We include a study carried out with sixteen discussion groups made up of children between 7 and 12 years old, in order to determine why this series is their favourite and justify how they perceive the violence it contains. 


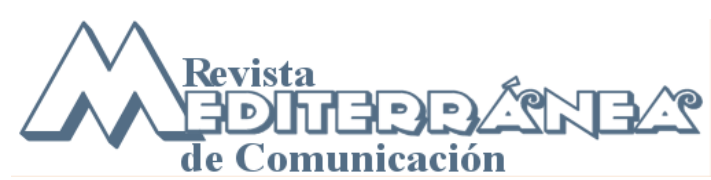

ISSN 1989-872X - Año2 (2011), pp. 125-139

\section{Palabras claves}

Ciencias sociales; televisión; medios; comunicación; teleducación.

\section{Key Words}

Social science; television; sociology; media; communication; tele-education.

Sumario: 1. Introducción. 2. Los medios de comunicación, un tema recurrente en Los Simpson. 3. Análisis de target y audiencia. 4. Metodología y resultados investigación. 5. Discusión. 6. Referencias bibliográficas.

Summary: 1. Introduction. 2. The mass media, a topic appellant in The Simpson. 3. Analysis of target and hearing. 4. Methodology and proved investigation. 5. Discussion. 6. Bibliographical references.

\section{Introducción}

Los Simpson llevan en antena ya veinte temporadas. En la actualidad, es la serie más vista en todo el mundo, con más de cuarenta millones de televidentes semanales en más de veinticinco países, además de las descargas de capítulos que permite la red, a través de You Tube, entre otras posibilidades.

Con más de 420 capítulos, es la serie estadounidense de animación con mayor número de entregas en la historia. En cuanto a la programación, ya en 1997, superó a Los Picapiedra como serie de animación con mayor tiempo de permanencia en prime time.

La primera emisión de Los Simpson como serie se remonta al 17 de diciembre de 1989. Como precedente, se programaron en televisión a modo de microespacio de continuidad en el intermedio del programa "El show de Tracy Ullman". El primero de los cortometrajes se emitió el 19 de abril de 1987. En su formato breve, tuvo tanta aceptación que pronto se apostó por su cambio a serie de veintidós minutos.

La serie llegó a España un año después, en 1991, cuando TVE compró los derechos de emisión a la FOX, dentro de un paquete junto a otros espacios. Los Simpson fue una serie que pasó desapercibida en La 2, con un capítulo semanal, primero en franja late-night de madrugada y, posteriormente, en otros intentos horarios que tampoco lograron emplazar a la audiencia.

La apuesta de Antena 3 por Los Simpson comenzó en 1994. El éxito se debió al acierto en la franja de mediodía, antes del informativo. Como se evidencia en los estudios de audiencia, esta es la segunda banda horaria estelar, sólo precedida por el prime time nocturno. Además, tras el éxito en el mediodía, también se ha programado varias ocasiones en prime time, consiguiendo también importantes cifras en cuota de pantalla.

La televisión digital terrestre, TDT, ha abierto nuevas opciones de ver la serie en distintos 
horarios en los que se redifunden sus capítulos, en los canales Antena Neox y FOX. La popularidad de la serie genera una fidelización en la audiencia, lo que repercute en que muchos de sus seguidores o fans se interesen por ver más de una vez los distintos episodios, incluso por llegar a aprenderse tramas y diálogos.

Esta comedia de situación posee un rico palmarés, con veintiún Premios Emmy, veintiún Annie, tres Génesis, ocho Internacional Monitor y cinco Environmental Media. "Homer, Bart, Lisa, Marge, Barney, Otto, Moe, son, sin ellos saberlo, gurús en posesión, prácticamente, de todas las pistas necesarias para sobrevivir en el mundo de los negocios"1 (Montero y Galán, 2008: 17).

La rentabilidad de la serie queda demostrada en los más de 3.400 millones de euros que ha ingresado la FOX desde que comprara sus derechos. Sin duda un éxito sin precedentes, pero ¿cuáles son las claves de la calificada por la revista Time como "la mejor serie del siglo XX"?

Los principales motivos por los que Los Simpson registra la citada cosecha de éxitos se deben a diversas variables que podemos clasificar en cuatro apartados:

- Formato atractivo para los niños, con dibujos animados cuya composición se caracteriza por el uso de figuras geométricas con trazos muy marcados triangulares (ejemplo en el diseño del cabello de Bart, Maggie o Lisa), circulares (ojos de los personajes) o muy redondeados (cuerpos, manos). Así mismo, las facciones de los personajes son exageradas (ojos y dientes, por ejemplo). Se cuida especialmente el cromatismo, con la utilización de colores vivos y muy llamativos. El ritmo de la serie resulta ágil y constante en el cambio secuencial de escenarios y tramas. La música ambiental utiliza acordes y los personajes llaman la atención de manera habitual mediante gritos. Todos estos factores, unidos a la identificación con los personajes infantiles de los protagonistas son factores que ayudan a que el niño se enganche con la serie, sin importar los contenidos. En una investigación llevada a cabo en Bogotá con 1.200 niños trabajadores de entre 12 y 18 años, Uribe Sarmiento ${ }^{2}$ (2007: 340) advierte que el gusto por Los Simpson, como serie preferida por los niños es un proceso "articulado a las subjetividades infantiles", relacionadas con estrategias de identificación subjetiva, independientemente de la propuesta adulta: "Los procesos de subjetivación e identidad no se reducen a una dinámica de transmisión de conocimientos, actitudes y valores, en la que unos sujetos (los jóvenes y los niños) reciben pasivamente lo que otros (los adultos) consideran necesario para ellos...". Una de las conclusiones más interesantes de este estudio es que los niños no perciben el repertorio crítico que propone la serie, ni los argumentos de fondo, únicamente se quedan con la lectura de que es "un programa de dibujos animados divertido, esta lectura se comprende en el escenario de las máscaras que propiamente Los Simpson escenifican"33 (Uribe Sarmiento, 2007: 261). 
- Contenido basado en la sátira social para adultos. La crítica buslesca a las distintas formas de vida de una sociedad convencional, los diálogos con uso de la ironía y la exageración constante y las continuas referencias a temas en clave crítica, como el alcoholismo, la drogadicción, el absentismo laboral, el mal funcionamiento sanitario o la contaminación de una central nuclear, junto con las referencias a caricaturas de personajes populares o ilustres de todas las épocas y disciplinas, son los principales anclajes para el público mayor de edad. Además, en palabras de Irwin, Conard y Skoble ${ }^{4}$ (2009: 18), "la serie es lo bastante profunda e inteligente para garantizar cierto nivel de discusión filosófica". En opinión de Marín Correa (2006: 188), esta serie es "casi perfecta e inigualable en todo sentido" "Según este autor, "Con el tiempo (la serie) ha ido evolucionando para ser, además de entretenida, el inteligente reflejo irónico de la sociedad a la que se dirige"".

- La finalidad que persigue es el entretenimiento para todos los públicos, con algunas dotes culturales y muchas licencias frívolas, que consiguen la evasión de las distintas generaciones que se sientan juntas ante la pantalla. La frivolidad, en muchos casos, llega hasta un uso demasiado distendido e, incluso, vulgar del lenguaje. Algunos autores hacen referencia a la esfera de la riqueza lingüística como uno de los valores en el aprendizaje a través del visionado de series de dibujos animados. Y, en el plano opuesto, se refieren al "contralenguaje"7 (Rajadell, Pujol y Violant, 2005) como elemento desnutrido y contraproducente en algunas series, en las que la pobreza en la expresión queda reducida a monosílabos, muletillas, insultos y "palabrotas", algunas de las cuales encontramos de manera frecuente en Los Simpson.

Por tanto, es una serie confeccionada para un uso generalizado, con temas que son de referencia internacional y con personajes que logran identificar a cualquier perfil de target, sin importar la edad, sexo o clase social. En cuanto al rango del sexo, es una serie que gusta por igual. Este hecho no ocurre con otras, que tienen un carácter más masculino o femenino. Así, lo apunta Aguaded Gómez (2005), entre los resultados de una investigación llevada a cabo en Huelva, constata que "los chicos se decantan por los dibujos de las series japonesas, como Fox Kids, Bola del Dragón, Digimon, Power Ranger, donde la fuerza es un valor predominante para conseguir lo deseado o dibujos de fútbol: Oliver y Benjuí. Las chicas prefieren series más tranquilas y románticas como dibujos de Disney, Piolin o Pingu".

Podemos afirmar que Los Simpson da respuesta a los cuatro niveles posibles de percepción, atendiendo a las escalas que pueden considerarse en su lectura:

a) Como acompañamiento, durante la realización de otras tareas o mientras se come, cuando se utiliza como fondo sonoro que sólo se oye, aunque no se escucha.

b) Como visionado de las formas de los personajes, de los modos de operar tan excéntricos entre ellos. Este modo corresponde a un nivel de lectura de niños que no entienden el significado de las tramas, pero a los que les gusta el formato.

c) Como lectura textual de los argumentos, no llegando a comprender todo el mensaje 
que ofrecen las distintas tramas, pero sí recibiendo el contenido de manera literal.

d) Como interpretación completa del contenido, entendiendo qué aspectos se esconden detrás de cada gag y del trasfondo crítico de cada trama.

Por tanto, una serie que contempla todas las posibilidades de tipo de público no sólo en cuanto a edades, sino también respecto al nivel de preparación y tipo de aficiones. Todo ello es convenientemente estudiado durante los seis meses que tarda cada episodio en producirse, de la mano de un equipo de dieciséis guionistas.

\section{Los medios de comunicación, un tema recurrente en Los Simpson}

Durante las veinte temporadas que se mantiene en pantalla, la serie Los Simpson ha tratado todo tipo de temas y argumentos. Dadas las características de redifusión de una serie que permanece impertérrita, los temas que suele presentar son atemporales, sin alusiones a la actualidad del momento. De este modo, asistimos a episodios relacionados con el absentismo escolar, el cambio climático o las relaciones entre padres e hijos, entre otros muchos. No obstante, se plasman algunos temas al hilo de eventos especiales, planificados en agenda, tales como los Juegos Olímpicos, las fiestas de Navidad o Halloween.

En la serie, se observan constantes referentes culturales y a personajes históricos de toda talla y condición: Ghandi, Lenin, Hitler, Reina de Inglaterra, Toni Blair, y a Presidentes de EEUU, entre otros: Washington, Nixon, Rooselvelt, Reagan, Eishenwouer o Lincoln. Sin olvidar, al actual, Obama. Estas referencias son claves a la hora de enlazar con el público joven con formación.

Los grandes ejes entorno a los que gira esta serie son temas de carácter universal, tales como la educación, la ecología, la familia, las tradiciones, la sanidad, la religión,... De ahí que también sean interesantes para todos los públicos y más con el tratamiento caricaturesco en el que se parodia la sociedad, como un gran circo en el que todo se pone a prueba y se ridiculiza: la falta de valores, el culto al cuerpo, el fuerte consumismo, etc. En este sentido algunos autores denuncian la falta de ética en la que se inspira la serie, la cual puede afectar la formación de parámetros sociales de los niños que la ven. Como señala Ávila Muñoz (2008: 84), "Esta animación presenta uno de los posibles reflejos de la sociedad estadounidense, que usualmente se proyecta como fragmentaria y con poca solidez en cuanto a la integración de las familias (...), los niños importan gran cantidad de sus conocimientos y formas de actuar de lo que está en su entorno inmediato, y si son expuestos a este tipo de emisiones, pueden tomarlas como algo 'normal'. Es preocupante la manera en que son minimizados algunos problemas sociales, como el maltrato y abandono de ancianos y la falta de respeto a los maestros, entre otras cosas" ${ }^{\text {. }}$.

Los medios de comunicación son uno de los temas que, de manera endogámica, más se ha venido criticando en la serie, desde la violencia que trasciende la pantalla, hasta el espectáculo televisivo o el sensacionalismo de la prensa, sin olvidar el cine vacuo en diálogos o el lado oscuro de la publicidad. 
A lo largo de su amplia trayectoria, Los Simpsons han cosechado alabanzas y críticas casi a un mismo nivel. Sus detractores la consideran un esperpento moderno, una abominación que enarbola la bandera de la deformidad social y presenta valores destructivos del mundo occidental. Por el contrario, sus defensores aseguran que se trata de uno de los artefactos culturales más influyentes de nuestro tiempo. Lo cierto es que no resulta fácil encuadrarla; no es una serie conservadora ni progresista. No obstante, hay una realidad constatable: Los Simpsons defienden la familia como institución, como salvaguarda de valores correctos y como refugio de la sociedad contemporánea.

Homer, Marge, Bart, Lisa y Maggie conforman un grupo que, aunque disfuncional, es nuclear. Cenas alrededor de la mesa, asistencia semanal a la iglesia del Reverendo Lovejoy, viajes familiares. La serie está plagada de momentos en los que Los Simpsons dejan a un lado sus diferencias para reunirse en torno a un medio, la televisión. Desde la propia cabecera de la serie, en la que se nos presenta a los protagonistas, queda patente ese nexo de unión. Homer se desentiende de sus labores "profesionales" del mismo modo en que Bart deja sin terminar su castigo, Lisa escapa apresurada de su clase de música y Marge abona rápidamente el importe de su compra en el supermercado. Todos corren por las calles de la ciudad, apremiados por "algo" que les llama y que es ineludible, la pantalla televisiva.

La serie se retroalimenta de la crítica indirecta al medio que la contiene, siendo la televisión uno de los contenidos centrales. Como apuntan Monterde Ferrando, Barcia González y Martínez Otero (2009), uno de los valores negativos de la familia es precisamente la "omnipresencia de la televisión", dado que "En todo capítulo podemos observar a cualquier miembro de la serie ante el televisor. Ésta se muestra como un elemento absoluto e imprescindible. Tenemos el ejemplo en el cual Homer pierde la noción de la realidad al no disponer de la televisión..."

\subsection{La televisión Simpson}

Dado que la televisión es, en gran medida, el fiel reflejo de la sociedad, resulta inevitable dedicar unas líneas a retratar, a grandes rasgos, cómo es Springfield. La sociedad es anacrónica, aislada de influencias exteriores y encerrada en sí misma. Se trata de un lugar imposible de situar geográficamente y en el que sus gentes parecen haber quedado ancladas en patrones de conducta y hábitos de vida pasados. Desde la distribución de la propia urbe (organizada en torno a una Central Nuclear, eje de la vida industrial) que recuerda a los falansterios de siglos pasados hasta las relaciones interpersonales entre sus habitantes, Springfield puede retratarse como un lugar localista y aislado del mundo. Y debido a ese localismo no es de extrañar que la cadena más seguida de la televisión Simpson sea el Canal 6, de producción local. Las estrellas mediáticas viven y trabajan en Springfield, y no es extraño verlas por sus calles o en los plenos en el Ayuntamiento. 
Kent Brockman, afamado y galardonado periodista springfieldiano, es el conductor de los informativos de Canal 6. Ojo en Springfield, Línea Inteligente, La Gente de Kent o los propios servicios informativos de la cadena tienen como presentador a este adalid de la subjetividad y el sesgo, del interés y la falsedad, de la falta de imparcialidad y de la pérdida de excelencia. Todos los programas de Brockman están manchados con los criterios que rigen su trayectoria, dando máxima cobertura a temas banales y fútiles sólo para conseguir audiencia. Kent Brockman es un mal profesional. No obstante, la sociedad de Los Simpsons le otorga la máxima credibilidad, siendo su informativo el más seguido de toda la televisión. Y lo que Brockman es para los adultos lo es Krusty, el Payaso, para los niños. Un personaje enfermo, alcohólico, aficionado a la pornografía, jugador y cercano al mundo de las drogas es quien reúne todas las tardes a los pequeños. En él confían los padres gran parte de la educación de sus hijos, en un acto de irresponsabilidad, dado que a ninguno de ellos parece preocuparles. Los valores que Krusty inculca en los niños se alejan de los correctos; desde sus afirmaciones enfocadas al consumismo exacerbado hasta los contenidos que ofrece en su programa (encabezados por El show de Rasca y Pica, una serie de animación que narra las distintas formas que ingenia un ratón para asesinar a un gato).

Este es el reflejo de la industria televisiva en Los Simpsons, representada por unos personajes alejados de cualquier criterio de excelencia, pero que gozan de una amplísima aceptación entre la sociedad amarilla.

\subsection{Los periódicos Simpson}

Aunque de una manera mucho más epidérmica que la televisión, los periódicos tienen también su representación en Los Simpsons. El Comprador de Springfield, periódico de edición local, es el único diario que se compra y se consume en la ciudad. No goza ni de lejos de la aceptación que sí tiene la televisión, y su reflejo en la serie no puede ser más mercantilista. En el capítulo Homer, crítico de cocina (temporada 11) se muestra la redacción del medio de comunicación como un lugar en el que nadie escribe, nadie investiga y nadie trabaja; los redactores dedican su tiempo a telefonear a los vecinos para convencerles de la necesidad de suscribirse a la publicación. En el episodio Al filo del panfleto (temporada 15) la trama vuelve a centrarse en el rotativo, en el que el redactor jefe irrumpe en la sala de redacción y, lejos de reprochar la actitud de los profesionales a su cargo, exclama: "¿quién es capaz de dar un bombo desproporcionado a una noticia?...".

Televisión y periódico, ambos sensacionalistas y amarillistas; pero también los máximos representantes del periodismo en Springfield, dibujando una sociedad teleadicta, que adolece de inquietud intelectual y que vive anclada en el pasado y en el ostracismo.

\subsection{El cine Simpson}

La industria cinematográfica también tiene su reflejo en la serie. Los cinéfilos reconocen al instante multitud de alusiones directas a citas y secuencias clásicas de la historia del cine. 
Parodias de grandes películas como Ciudadano Kane, Un tranvía llamado deseo, Psicosis, Casablanca o Indiana Jones tienen un papel destacado en muchos de los capítulos (quién no recuerda a Homer rodando en ropa interior por las escaleras mientras intenta alcanzar a Bart, emulando la secuencia en la que Harrison Ford debe huir para no ser aplastado por una gran roca en Indiana Jones, en busca del arca perdida). Pero más allá de la más o menos fiel representación de filmes adaptados al mundo amarillo, en Los Simpsons aparecen estereotipos hollywoodienses como la asociación de McBain, personaje interpretado por el actor Rainier Wolfcastle, con la saga de películas de Rambo y Arnold Schwarzenegger. Ambos, McBain y Rambo, son personajes musculosos, beligerantes y combativos, aunque quizá en Los Simpsons podamos mirar más allá. Martín Correa (2006: 155) señala una vinculación entre las tramas de las películas de McBain y la relación entre los Estados Unidos con sus vecinos Latinoamericanos. Este autor asegura que estas películas "apuntan a los países latinos como focos de narcotráfico, terrorismo y subdesarrollo mientras que los norteamericanos se glorifican como superpoderosos"11.

\subsection{La publicidad Simpson}

La sociedad de Springfield es anacrónica y arcaica. No obstante, y a pesar de que se trata de una comunidad aislada y localista, el consumismo y el modelo de "usar y tirar" tiene fuerte implantación en la forma de vida de los springfieldianos. Imbuida por su afán de reflejar la actualidad, la serie nutre a sus tramas de multitud de alusiones al modelo consumista que impera hoy en las sociedades capitalistas occidentales. Y una vez más, se sirve de Homer, el padre de familia, para dibujar el estereotipo de persona dependiente de los bienes materiales y, por supuesto, de la publicidad. El padre de familia se erige como eje central de muchas de las tramas, que normalmente giran en torno a su inconsciencia y osadía. No obstante, conviene señalar que Homer es un hombre emprendedor, que busca en todo momento prosperar para así aumentar su poder adquisitivo y su nivel de vida, algo meritorio que podría convertirlo en un padre virtuoso, si no fuera porque sus objetivos son egoístas e irresponsables. El señor Simpson es dependiente de la publicidad. Homer no filtra, no razona; únicamente ve y compra. De ahí que vea en su vecino, el honorable Ned Flanders, su principal enemigo. No ambiciona su quietud, su responsabilidad, ni su sosiego, sino su dinero, su posición y su capacidad para llevar una vida mucho más consumista.

Lo cierto es que a Homer no le importa provocar un accidente en la carretera por querer pararse ante una valla comercial. Un mensaje le anuncia apertura de una escuela de payasos, auspiciada por la marca de Krusty y, aunque él sabe que ese no es su ideal, no es capaz de luchar con lo que una valla de publicidad le ha ordenado (Homie, el payaso, temporada 6).

Dada su teleadicción, el padre de familia es incapaz de hacer caso omiso a los mensajes comerciales que ofrece la televisión. En ella, encuentra la solución a sus problemas y la respuesta a sus dudas. Y conociendo ya las características de la televisión Simpson, no es de extrañar que se bombardee a los springfieldianos con anuncios de alcohol o tabaco. 
La cerveza Duff, bebida preferida del patriarca, publicita su producto acudiendo a la siguiente fórmula: “¿Parado?, ¿sin empleo?, ¿sobrio? Se ha pasado usted el día tumbado en casa, pero ha llegado la hora Duff. Duff, la cerveza que hace que los días pasen volando" (La odisea de Homer, temporada 1). Lo mismo ocurre con los cigarrillos Laramie, que utilizan un certamen de belleza infantil para intentar captar a los "fumadores potenciales". En sus anuncios, las aspirantes al título se sienten "tan felices como el fumador que da la primera calada en la mañana" (Miss Springfield Junior, temporada 4).

En definitiva, los productores de los Simpsons retratan una sociedad esclava del estilo de vida consumista llevado a extremo.

\section{Análisis de target y audiencia}

Los Simpson es clasificada como una serie destinada como target de partida a mayores de edad, atendiendo a las licencias en el lenguaje utilizado en diálogos y tramas. Según exponen Irwin, Conard y Skoble (2009: 18), "Los Simpson es, sin duda, una serie para adultos, y es superficial menospreciarla sólo a causa del soporte animado y la popularidad"12.

Sin embargo, la imagen promocional de la serie, representada en las autopromociones, contempla el rostro más amable e ingenuo de los personajes, con situaciones descontextualizadas y con escenas de los momentos más divertidos. De este modo, se despierta el interés de los niños y se capta al doble perfil del público, llegando a una reconversión del target hacia el perfil familiar. En Los Simpson, todos estamos representados, lo que la convierte en una serie que gusta a toda la familia.

En cuanto a las cifras de audiencia, la evidencia de su éxito quedó patente ya en la segunda temporada de emisión en USA, cuando se situó, en 1992-1993, entre los 30 primeros programas más vistos, haciendo que por primera vez la FOX se situase en la cima de las cuotas de pantalla. Con similar tendencia, en la cadena privada de nuestro país en la que se emite, Antena 3, se encuentra desde sus inicios en los primeros puestos del ranking, con un promedio de share por encima del $20 \%$. Como ejemplo, en el informe de audiencia de TN Sofres de enero de 2010, una de sus emisiones (la del día 20 de enero) se situaba en tercer lugar en el ranking, llegando a verla 3.276.000 de personas $^{13}$.

Del mismo modo, en el terreno de los canales de TDT, se convierte en líder de audiencia de Antena Neox, con una cuota de pantalla superior a un $2 \%$, cifra notable considerando la fragmentación existente de canales. De hecho, en investigaciones recientes (Moreno Rodríguez, 2009), en las que se incorporan todos los canales existentes, junto con los de TDT, la preferencia infantil por excelencia sigue siendo Los Simpson, lo que repercute, precisamente, en que Antena Neox sea el canal más conocido y consumido por los niños ${ }^{14}$.

Respecto a los perfiles de audiencia, las cifras corroboran cada año que es la serie más 
vista en la última década por los niños y jóvenes, junto con otras series no dirigidas precisamente a este target. En este sentido, Núñez Ladevéze, Gómez Amigo y Vázquez Barrio (2007: 272) apuntan que "en relación con el tema de la disonancia pragmática entre criterios y conductas de padres y tutores, se puede apreciar que, cuantitativamente hablando, los niños ven otra cosa distinta de la programación específica infantil..."15.

Diferentes investigaciones realizadas dentro del ámbito de la Comunicación Social, avalan Los Simpson como la serie preferida por el público más joven. Por ejemplo, según datos de un estudio llevado a cabo con 440 niños entre 7 y 12 años en la Comunidad de Madrid (Marta Lazo, 2005), ocupa el primer lugar en el ranking de sus dibujos animados favoritos, con 42,1\%, seguidos a gran distancia de "Campeones" (18,9\%), "Doraemon" (14,3\%), "Pokémon" (12,5\%) y "Dragon Ball” $(11,4 \%)^{16}$.

\section{Metodología y resultados investigación}

El objetivo del análisis es determinar cómo definen y valoran los niños Los Simpson, en qué medida consideran que es o no una serie destinada a ellos, y porqué razones justifican que la ven. Y, por otro lado, de qué forma advierten las imágenes violentas integradas en la serie, las cuáles pueden ser discutibles como correctas en el plano ético de una serie dirigida a "todos los públicos".

La metodología aplicada consistió en una investigación de tipo cualitativo con dieciséis grupos de discusión de carácter mixto en cuanto a género. Los grupos, se repartieron atendiendo a la edad, con divisiones: de 7 a 9 años y de 10 a 12 años, con el fin de analizar las diferencias en la percepción de la serie en ambos segmentos. Otra de las variables que se consideró en la distribución de los grupos fue la cantidad de consumo televisivo, llevando a cabo un reparto entre los niños que veían menos de dos horas al día y los que superaban esta cantidad.

En la mayoría de los grupos, los niños participantes declaraban que suelen ver Los Simpson, asiduamente, en horario de sobremesa acompañados de sus padres y/o hermanos, y, en menor medida, solos.

En la sesión llevada a cabo en cada uno de los grupos, en primer lugar se visionaba un fragmento con imágenes violentas para observar cómo interpretaban los niños el contenido. La secuencia elegida pertenecía al capítulo número 241, con el título Misionero Imposible, correspondiente a la temporada 11. En el capítulo, se ve a Homer y Bart sentados enfrente de la televisión viendo un programa violento, en el que varios hooligans se pelean de manera muy agresiva y la madre de uno de ellos, los separa echándoles lejía en la cabeza y en los ojos.

En general, los niños advertían los aspectos relacionados con la violencia expresa en las imágenes y describían de este modo los detalles que más les habían impactado: "Bart $y$ Homer están viendo la tele, una serie de que dos chicos beben, se emborrachan y rompen una botella, y se empiezan a pelear", "cuando dicen 'una patada en el trasero', cuando le echa lejía y cuando dice la palabrota, mal...", "Bart dice a Homer: ¿estás viendo 
la tele de terror? Y dice: pues sí, hay veces que se dan patadas en el culo o se pelean. $Y$ dice: dabuten. Y dicen eso son palos de hockey y dice la madre 'no tenéis pelotas"'.

Los grupos de niños más mayores, de 10 a 12 años, ahondaban más en el contenido y criticaban que Homer dejara ver esas imágenes a Bart. Además, incluso, cuestionaban que el capítulo al que pertenece la secuencia vista se haya emitido en televisión y no dudaban en señalar que ellos lo eliminarían de la programación. Estas últimas valoraciones se realizaban, precisamente, en grupos cuyos componentes solían dialogar con los padres acerca de los contenidos que ven: "el hecho de que Homer le deje ver esa serie a Bart es brutal", "es un poco bélico que se maten a tortas, es una burrada", "Eso está muy mal, ya no me gustan tanto 'Los Simpson'... después de lo que hemos visto", "...¿¿o han echado en la televisión que vemos?, ¿en Antena 3, lo han echado?, ¿en serio?", "Eso, es para decirle a la directora que, o lo quita, o quita la televisión".

En este sentido, resultan clarificadoras las palabras de Monterde Ferrando, Barcia González y Martínez Otero (2009), quienes manifiestan que "Lo más importante que debieran saber los productores es que no pueden sacrificarse los valores democráticos en el altar de la diversión. No todos los argumentos son convenientes, deontológicos"17.

Siguiendo con la misma horquilla de edad (10-12 años), los grupos de niños que acostumbraban a ver menos dos horas la televisión insistían en la importancia de ver la serie acompañados de adultos, debido a que esta serie es "un poco fuerte" o a que "hay demasiada violencia", con el fin de que expliquen o limiten lo que es más agresivo: "Es para niños, pero para verlo con mayores...Yo, a veces, veo esta serie con mi primo porque, así, me explica cosas o, si hay algo fuerte, me dice que me vaya o baje el volumen", "Es para niños pero más mayores. Por el contrario, quienes superaban la frontera de las dos horas de consumo diario suelen indicar que está destinada a niños, lo que justifican advirtiendo que "no dicen casi palabrotas" o "que el lenguaje es normal".

Por lo que respecta a los grupos de niños de entre 7 y 9 años, encontramos respuestas con diferentes parámetros. En algunos casos, señalaban que se trata de una serie que, unas veces está destinada a niños y otras sólo a adultos, de modo que la clasifican en función del tipo de contenido que se emita en sus diferentes entregas: "Algunas veces ponen cosas de niños $y$, otras, es más para mayores, porque, a veces, ponen cosas que no tienen mucho sentido para los niños", "Para mayores y para niños...". "(¿Pensáis que los niños los pueden ver?) Algunos capítulos, sî".

Otros participantes relacionaban que es para niños atendiendo a diversos criterios:

- $\quad$ al contenido (en referencia a que no se introducen "palabrotas"):

- "Para niños... no dicen palabrotas".

- al horario (puesto que es a una hora considerada permitida).

- "De niños... No es a mala hora y no dicen muchos tacos". 
- al tipo de programa (en este sentido, simplemente por el hecho de tratarse de dibujos animados, piensan que forman parte del perfil de destinatarios de la serie. Así, relacionan la animación con el público infantil, al que pertenecen).

- "Para adultos, no mucho porque son dibujos".

- "para niños porque, como son dibujos, a lo mejor les gustan y les interesa".

Cabe insistir en que, a pesar de que algunos niños consideran que es una serie destinada a mayores, ellos suelen verla. Además, en ocasiones, la clasifican en función de su edad, con objeto de justificar que la pueden ver, independientemente de la cantidad de tiempo que estén diariamente ante la pantalla.

- Niño 7-9 años: "Para mayores de 7 ó 13 años" (Esta cita pertenece, precisamente, a un niño que tiene 7 años y que acostumbra a ver la serie con su hermano que tiene 13).

- Niño 10-12 años: "Esa serie es para mayores por lo que dicen (...). 'Los Simpson' los veo para mayores de 10 años, normalillo" (este niño también clasifica la serie atendiendo a su edad, ya que él tiene 11 años, así justifica que puede verla).

En cuanto a la valoración que hacen de Los Simpson, destaca la calificación expresa de que "no es educativa", que "tiene componentes violentos", pero pese a ello justifican como ya hemos señalado- que se trata de una serie "infantil".

\section{Discusión}

Los Simpson se ha afincado en la programación televisiva como uno de los espacios históricos, con veinte años en la parrilla. Una de las claves de su éxito es la combinación de diferentes sistemas expresivos dirigidos cada uno de ellos en mayor medida a un target de audiencia. En el caso, del formato de animación a niños y el contenido en off para los adultos.

Esta serie se ha convertido en la predilecta del público infantil. Las cifras de audiencia la sitúan de manera periódica en la primera más vista en el ranking de los niños entre 4 y 12 años.

El método de los grupos de discusión sirve para otorgar la voz a los niños y observar la reconstrucción que hacen de la serie a través de sus juicios de valor y argumentos. Asimismo, realizan una validación de los contenidos vistos en función de sus propias experiencias.

Los niños denuncian de manera explícita el contenido de la serie cuando observan imágenes muy violentas, incluso llegan a criticar la imagen de que Homer deje ver a Bart una serie de temática agresiva. Esta valoración contrasta con el interés que los niños tienen por la serie, de tal modo que utilizan su propia edad como criterio para la clasificación y se auto-aprueban o validan como audiencia apta para ver los contenidos 
que presenta. De esta forma, defienden el hecho de poder verla y lo justifican con todo tipo de argumentos: por el contenido, ya que no se incluyen tantas "palabrotas" como en otras; por el horario, al ser a mediodía, y por el formato, al tratarse de un espacio de dibujos animados.

La edad de los niños es una variable diferenciadora a la hora de saber interpretar el contenido de las imágenes, distinguir en mayor medida los aspectos violentos que presenta y criticar su emisión. Asimismo, el hecho de visionar menos de dos horas al día la televisión también repercute en que filtren más el contenido de la serie y adviertan en mayor medida la violencia de las imágenes.

A pesar de que los niños justifican que es una serie que pueden ver, ellos mismos aconsejan verla acompañados de adultos, debido al carácter impactante que presenta.

Los Simpson es una serie que contiene continuas referencias a los medios de comunicación (televisión, prensa, publicidad, cine,...), este tipo de temas pueden utilizarse para aplicar en contextos educativos relacionados con los mass media. Por un lado, como crítica de los contenidos menos éticos que contienen los medios y, por otro, como argumentación de los usos y consumos menos propicios que lleva a cabo la audiencia. Como ejemplo, la correlación entre los constantes imputs publicitarios y el consumismo permite contemplar y valorar este último aspecto, entre otras muchas dimensiones y facetas que presentan los argumentos de esta ya mítica serie televisiva.

\section{Referencias bibliográficas}

Aguaded Gómez, Ma C. (2008): «El abuso de la televisión por parte de nuestros alumnos: cómo, cuándo y por qué». Comunicar, 25, Huelva: Grupo Comunicar, Actas Congreso Hispanoluso de Comunicación y Educación.

Ávila Muñoz, P. (2008): «Importancia de la mediación de los padres ante la exposición de sus hijos a los medios masivos de comunicación». Sphera Pública, 8, Universidad Católica de San Antonio de Murcia.

Irwin, W; Conard, M. T. y Skoble, A. J. (2009): Los Simpson y la filosofía. Barcelona: Blackie Books.

Marín Correa, J. P. (2006): Detrás de los Simpson. Madrid: Ediciones del Laberinto.

Marta Lazo, C. (2005): La televisión en la mirada de los niños. Madrid: Fragua.

Monterde Ferrando, R.; Barcía González, A.; y Martínez Otero, J. (2009): «Valores y contravalores en la ficción televisiva. Un estudio aplicado al caso de Los Simpson», [en línea], www.observatoriovermastv.org/Microsoft\%20Word\%20-\%20los\%20simpson.pdf, (consultado el 19 de junio de 2009). 
Moreno, Maㅡ. D. (2009): «La TDT impulsa la multiplicación de canales infantiles», [en línea]. EDUTEC, Revista Electrónica de Tecnología Educativa, 28. [Fecha de consulta: 15/02/2010], http://edutec.rediris.es/revelec2/revelec28/, (consultado el 23 de enero de 2010).

Montero, F. y Galán, R. (2008): La empresa según Homer Simpson. Barcelona: Gestión 2000 .

Núñez Ladevéze, L.; Gómez Amigo, S.; y Vázquez Barrio, T. (2007): «La audiencia infantil en la CAM». Ámbitos, 16, Sevilla: Universidad de Sevilla, pp. 257-281.

Rajadell, N.; Pujol, Ma A.; y Violant, V. (2005): «Los dibujos animados como recurso de transmisión de los valores educativos y culturales». Comunicar, 25, Huelva: Grupo Comunicar, Actas Congreso Hispanoluso de Comunicación y Educación.

TN SOFRES (2010): «Boletín mensual de audiencia de TV», enero, [en línea], http://www.tns-media.es/actualidad/audiencia-tv/, (consultado el 17 de febrero de 2010).

Uribe Sarmiento, J. J. (2007): «Las máscaras identitarias o Los Simpson. Aproximación al consumo cultural de los menores trabajadores de Bogotá», Maguaré, 21, Universidad Nacional de Colombia, pp. 335-362.

\section{Notas.}

${ }^{1}$ Montero, F. y Galán, R. (2008): La empresa según Homer Simpson. Barcelona: Gestión 2000, p. 17.

2 Uribe Sarmiento, J. J. (2007): "Las máscaras identitarias o Los Simpson. Aproximación al consumo cultural de los menores trabajadores de Bogotá", Maguaré, 21, Universidad Nacional de Colombia, p. 340.

${ }^{3}$ Uribe Sarmiento, J. J., op. cit., p. 261.

${ }^{4}$ Irwin, W; Conard, M. T. y Skoble, A. J. (2009): Los Simpson y la filosofía. Barcelona: Blackie Books.

${ }^{5}$ Marín Correa, J. P. (2006): Detrás de los Simpson. Madrid: Ediciones del Laberinto, p. 188.

${ }_{7}^{6}$ Marín Correa, J. P., op. cit., p. 188.

${ }^{7}$ Rajadell, N.; Pujol, Mํㅡㄹ A.; y Violant, V. (2005): "Los dibujos animados como recurso de transmisión de los valores educativos y culturales". Comunicar, 25, Huelva: Grupo Comunicar, Actas Congreso Hispanoluso de Comunicación y Educación.

${ }^{8}$ Aguaded Gómez, $M^{a}$ C. (2008): "El abuso de la televisión por parte de nuestros alumnos: cómo, cuándo y por qué”. Comunicar, 25, Huelva: Grupo Comunicar, Actas Congreso Hispanoluso de Comunicación y Educación.

9 Ávila Muñoz, P. (2008): "Importancia de la mediación de los padres ante la exposición de sus hijos a los medios masivos de comunicación". Sphera Pública, 8, Universidad Católica de San Antonio de Murcia.

${ }_{10}$ Monterde Ferrando, R.; Barcía González, A.; y Martínez Otero, J. (2009): "Valores y contravalores en la ficción televisiva. Un estudio aplicado al caso de Los Simpson", [en línea], www.observatoriovermastv.org/Microsoft\%20Word\%20-\%20los\%20simpson.pdf, (consultado el 19 de junio de 2009).

${ }^{11}$ Marín Correa, J. P., op. cit., p. 155.

${ }^{12}$ Irwin, W; Conard, M. T. y Skoble, A. J., op. cit., p. 18.

${ }^{13}$ Cfr. TN SOFRES (2010): "Boletín mensual de audiencia de TV", enero, [en línea], http://www.tnsmedia.es/actualidad/audiencia-tv/, (consultado el 17 de febrero de 2010).

${ }^{14}$ Cfr. Moreno, Mํㅡㄹ. D. (2009): "La TDT impulsa la multiplicación de canales infantiles", [en línea]. EDUTEC, Revista Electrónica de Tecnología Educativa, 28. [Fecha de consulta: 15/02/2010], http://edutec.rediris.es/revelec2/revelec28/, (consultado el 23 de enero de 2010). 
${ }^{15}$ Núñez Ladevéze, L.; Gómez Amigo, S.; y Vázquez Barrio, T. (2007): "La audiencia infantil en la CAM". Ámbitos, 16, Sevilla: Universidad de Sevilla, p. 272.

${ }^{16}$ Cfr. Marta Lazo, C. (2005): La televisión en la mirada de los niños. Madrid: Fragua.

${ }^{17}$ Monterde Ferrando, R.; Barcía González, A.; y Martínez Otero, J., op. cit..

Este trabajo es uno de los proyectos desarrollados por el Grupo de Investigación en Educomunicación (GIEC), número S-82, dirigido por Carmen Marta Lazo en ese periodo y financiado por la Consejería de Ciencia, Tecnología y Universidad del Gobierno de Aragón, iniciado en 2008 y finalizado en 2010. 